\title{
NÃo-Individualidade EM MecÂnica QuÂnTICA
}

\author{
VALÉRIA GRADINAR
}

\begin{abstract}
The non-relativistic quantum mechanics offers us conditions to consider at least two possible metaphysical packages, but incompatible between themselves: metaphysics of individuals, and metaphysics of non-individuals. In addition, the standard formalism is compatible with both the ontologies, without the theory being decided for either of them. From this particular kind of situation, the thesis of the underdetermination of metaphysics by physics can be established. Actually, it can be found, among scientists and philosophers, defenders of one, or another ontology, as well as those who do not address the issue, given that theory on its own does not decide. This means that if we make a choice for one of these packages, it will be happing in a metaphysical field, increasing a lot the philosophical discussions about individuality of quantic objects in quantum physics. From a naturalized methodological view, we present the issues from those defend the individuality of quantic objects, and from those, include us, defend non-individuality, focusing two approaches: (i) the ontological one, in which the fail of IIP as individuation principle is discussed; and, (ii) the logical one, in which non-reflexive logics, as well as a quasi-set theory became more suitable for representing the non-individuals. In this paper we stand for the choice of non-individuals ontology becomes more plausible, and should be taken in account seriously, opening up possibilities for ontological pluralism.
\end{abstract}

Keywords: Metaphysical underdetermination; quantum mechanics; non-individuals.

\section{Introdução}

A natureza metafísica das entidades as quais são tratadas pela mecânica quântica não-relativística ${ }^{1}$ tem sido objeto de discussão na literatura quanto à individualidade ou não-individualidade dessas entidades que, pode-se supor, subjazem à formulação teórica. O problema a ser enfocado refere-se ao fato de que a mecânica quântica nos 'sugere' uma dupla resposta, ou seja, ela admite, pelo menos, duas noções incompatíveis de entidades que podem povoar a ontologia associada ao seu formalismo: indivíduos e não-indivíduos e, sobretudo, a teoria não nos sinaliza de modo decisivo por qual dessas noções devemos tratar os objetos quânticos. Aqueles que consideram uma perspectiva científica, como recurso exclusivo para as questões ontológicas, enfrentam um problema, isto é, enfrentam uma subdeterminação metafísica proporcionada pela física, ou como também é chamada, a segunda tese da subdeterminação. (French 1998, p.95; French e Krause 2006, p.189-90).

No entanto, há alternativas. Assumir ambas as ontologias, em princípio, também é uma opção, não de forma a descrever a natureza ontológica dos seres em

Principia 18(1): 67-85 (2014).

Published by NEL — Epistemology and Logic Research Group, Federal University of Santa Catarina (UFSC), Brazil. 
geral, mas, sim, de forma a basear-se em uma perspectiva de estruturas. Tal perspectiva considera que os objetos são derivados de estruturas ou de relações, logo não podem ser considerados entidades metafísicas basilares. Por essa razão, objetos particulares com suas peculiaridades seriam entidades metafísicas secundárias e, nesse caso, a subdeterminação metafísica não entraria no rol das preocupações sobre sua natureza. Ao contrário, a subdeterminação metafísica seria aceita às custas de uma visão diferente da visão clássica do realismo: o realismo estrutural ontológico (REO) (French 2011). Porém, segundo nossa interpretação, podemos dizer que a perspectiva do REO acaba por acrescentar mais uma entidade a ser descrita metafisicamente, de modo que teríamos que dar conta das relações, além dos indivíduos e não-indivíduos, como escolhas metafísicas. De qualquer modo, no que concerne ao tipo de visão do realismo que nos comprometemos, devemos ter em conta que há dois modos pelos quais podemos tratar essa questão metafísica: um realismo de objetos ou um realismo de estruturas.

Considerando que o conceito de objeto é vago e não intencionamos tratá-lo de forma específica, nossa abordagem refere-se ao termo de modo geral, através da perspectiva do realismo objetual, o qual considera os objetos particulares como a última instância metafísica dos objetos em geral e, desse modo, teremos que dar conta do que consistem esses objetos: se indivíduos ou não-indivíduos. Encontramos atualmente, entre cientistas e filósofos, aqueles que advogam por uma ontologia ou pela outra, gerando um impasse que fomenta muito o debate filosófico.

O que nos parece, a princípio, é que, se quisermos superar a subdeterminação para qualquer um dos lados, deveremos buscar as respostas baseando-nos em outros fatores que não aqueles advindos da teoria, ou seja, não advindos dos dados científicos. Em outras palavras, só temos subdeterminação porque confinamos nossa análise aos recursos da teoria e, dessa forma, qualquer uma das escolhas ontológicas dependeria de aspectos não-formais da ciência. Por um lado, isso representa um problema àqueles que não desejam considerar a ontologia sob esferas transcendentais nas suas conjecturas, mas também não é menos problemático considerar essas questões ontológicas exclusivamente através das teorias científicas, como pretendiam os defensores da Received View. De certa forma, parece que a subdeterminação é um bom argumento contra a restrição dos recursos metafísicos no âmbito da teoria científica que estamos estudando. Ou seja, os critérios para qualquer uma das escolhas é de ordem metafísica e não científica. Assim, poderíamos questionar: em que princípios basear uma escolha?

\section{Os não-indivíduos}

A partir das considerações acima, concentraremos a problematização dos não-indivíduos em três esferas de investigação científica, as quais relacionam-se entre si e as

Principia 18(1): 67-85 (2014). 
quais julgamos pontuais: ontológica, metodológica e lógica.

\subsection{Questão ontológica}

Quando tratamos com objetos macroscópicos, intuitivamente, os identificamos através de relações com outros objetos do domínio, de modo a diferenciá-los e caracterizá-los, fornecendo-lhes uma identidade e, consequentemente, uma individualidade. Mas, conceitualmente, a individualidade das entidades em geral é descrita por algum tipo de teoria de individuação. Um indivíduo pode ser descrito, por exemplo, como aquela entidade que obedece a alguns princípios de individuação, como o célebre Princípio de Identidade dos Indiscerníveis, abreviadamente PII, comumente usado como princípio auxiliar de uma das teorias de individuação (teoria de feixes de propriedades). Este princípio, responsável pela descrição da unicidade da entidade, diz que objetos indiscerníveis compartilham as mesmas propriedades e por isso são idênticos, ou seja, são o mesmo objeto. Assim, conceitualmente falando, tratar a partícula quântica nos mesmos moldes em que são tratados os objetos da física clássica tornase problemático.

A interpretação ortodoxa da mecânica quântica propõe que os objetos quânticos sejam tratados como algo destituído de individualidade, pois 'a identidade dos elétrons se perdeu' (French e Krause 2006, p.293), isto é, podemos dizer, efetivamente, quantos elétrons há em um átomo de He, mas não podemos dizer qual é qual, não podemos dizer este ou aquele, ou seja, não podemos identificá-los. Aliás, Schrödinger já havia afirmado que "não se pode marcar um elétron, não se pode pintá-lo de vermelho" (Schrödinger 1935, p.131-2). Devemos lembrar que a questão da não-identidade da partícula quântica não é um problema epistêmico, mas, sim, um problema ontológico: trata-se de uma qualidade intrínseca do objeto quântico. Uma conclusão imediata fornecida dessa observação indica que os observáveis representam entidades que falham em satisfazer um dos principais princípios de identidade: o Princípio de Identidade dos Indiscerníveis.

A partir da definição de individualidade por este princípio, objetos indiscerníveis contariam como um único objeto, e sendo assim, a individualidade estaria implicada na indiscernibilidade e na identidade. O problema não se refere apenas ao fato de que as partículas na mecânica quântica são indistinguíveis e, por isso, seriam destituídas de individualidade, mesmo porque as partículas clássicas também podem ser indistinguíveis. Mas, o que permite comparar as partículas quânticas às da mecânica clássica consiste na diferença entre os comportamentos estatísticos dessas partículas em relação ao Permutation Symmetry (French e Rickles 2003, p.213-4). As partículas clássicas podem ser indistinguíveis por suas propriedades intrínsecas, mas não obedecem ao Permutation Symmetry, ou seja, permutar partículas clássicas indistinguíveis sempre dá origem a um estado diferente, devido, pelo menos, a sua posição

Principia 18(1): 67-85 (2014). 
espaço-temporal. Diversamente, as partículas quânticas obedecem ao princípio de não-observabilidade das permutações, ou seja, não há diferença entre os estados antes da permutação e depois da permutação. A identidade nos objetos quânticos perde o sentido pelo motivo de que as partículas quânticas 'são invariantes por automorfismo', por exemplo, no caso de partículas em emaranhamento.

Claro que, ao invés de propriedades, poder-se-ia atribuir a individualidade às entidades através das teorias dos substratos, o que solucionaria o questionamento sobre a validade do PII como princípio de individuação. O substrato transcende qualquer atributo, de modo a fazer do objeto particular algo único e, justamente, é essa atribuição do substrato, como componente ontológico mais intrínseco do objeto, que desempenha um papel individuador, entretanto, colocando a individualidade em um domínio transcendental. Mas, as teorias do substrato também enfrentaram algumas dificuldades, tais como: explicar a falta de acesso aos substratos, dizer o que é o substrato, ou mesmo, atribuir ao substrato uma categoria transcendental. Além disso, não parece muito confortável uma opção em que a individualidade seja realizada por algo que vai além de qualidades empiricamente detectáveis àqueles que têm uma perspectiva metafísica naturalizada (Arenhart 2012a, p.2).

Retomando o PII, podemos dizer que as noções de identidade e indiscernibilidade colapsam no mesmo conceito para descrever a individualidade. A noção de identidade, basicamente garantida pela unicidade do objeto particular através do PII, ao dizer que 'quando dois objetos possuem as mesmas propriedades, então eles são idênticos' compromete-se com a noção de indiscernibilidade, gerando uma implicação lógica. Podemos expressar o PII através de uma linguagem de segunda ordem do seguinte modo: $\forall x \forall y(\forall P(P(x) \leftrightarrow P(y)) \rightarrow x=y)$, onde $P$ é uma variável para propriedades. A conversa do Princípio da Identidade dos Indiscerníveis, conhecida como Princípio de Indiscernibilidade dos Idênticos, e que podemos chamar aqui de PII-c, traz a forma recíproca do PII: se dois objetos são idênticos, então eles são indiscerníveis. Devemos perceber que na conversa do PII deve valer o Princípio de Substitutividade, que afirma que objetos idênticos têm as mesmas propriedades e podem ser substituídos um pelo outro em qualquer contexto de forma que 'salva veritate' (preserva-se a verdade). Também podemos expressar o PII-c em uma linguagem lógica de segunda ordem: $\forall x \forall y(x=y \rightarrow \forall P(P(x) \leftrightarrow P(y)))$, onde $P$ igualmente é uma variável para propriedades. A conjunção entre o PII e a sua forma recíproca, o PII-c, formam a chamada Lei de Leibniz, que é uma lei lógica expressa em: $\forall x \forall y(\forall P(P(x) \leftrightarrow P(y)) \leftrightarrow x=y)$, a qual captura a relação de equivalência entre as noções de indiscernibilidade e identidade dos objetos.

Segundo uma perspectiva metafísica do PII, apresentam-se três versões que podem individualizar um particular na sua mais inerente propriedade, de acordo com alguns critérios de discernibilidade, sendo que uma violação destas versões comprometeria o princípio no seu propósito de individuação. Assim, a discernibilidade é 
caracterizada através das seguintes formas, excetuando-se a propriedade de autoidentidade: o PII(1), a forma mais fraca, afirma que não há dois indivíduos com as mesmas propriedades (inclui-se aqui também como propriedades as relações espaçotemporais); o PII(2), a forma menos fraca, exclui as relações espaço-temporais das propriedades dos indivíduos; e, o PII(3), a forma mais forte, inclui somente as propriedades monádicas, ou seja, as não-relacionais, que diz que não há dois indivíduos com as mesmas propriedades monádicas. Basicamente, tanto a versão PII(1) como a versão PII(2) necessitam de relações com outros indivíduos para cumprir o seu propósito de individuação, o que é debatido pelos opositores da teoria de feixes. Vale lembrar que o tratamento que damos a essas teorias de feixes de propriedades assume uma versão mais robusta do PII e, nesse sentido, fica claro que viola-se os pressupostos leibnizianos, ou seja, o PII passa a não cumprir seu propósito de princípio de individuação, pelo menos da maneira em que foi proposto. Nesse caso, somente o PII(3) poderia ser considerado como um princípio de individuação legítimo, levando-se em conta a independência de relações com outros indivíduos.

Visto dessa forma, não podemos aplicar essa mesma descrição a todos os objetos quânticos, uma vez que objetos quânticos indiscerníveis podem apresentar uma discernibilidade numérica, isto é, são indiscerníveis, porém contam mais de um. Citando novamente o exemplo de um átomo de He, seus dois elétrons são indiscerníveis à medida que estão em emaranhamento. No caso dos férmions, podemos dizer que são indiscerníveis nas suas qualidades intrínsecas, pois todos os valores esperados de qualquer férmion em estado de antissimetria deve ser o mesmo antes e depois de uma permutação, impedindo uma distinção através do PII. Sabemos que há dois elétrons no átomo de He, mas não podemos dizer qual é qual. Se um deles for trocado por outro qualquer, nada muda, pela condição imposta pelo Symmetry Postulate. Isto, supostamente, invalidaria o PII, referente à afirmação que diz que, se objetos são indiscerníveis, não pode haver mais do que um único objeto: eles são idênticos, ou seja, são o mesmo indivíduo. Dessa forma, a visão do PII, tradicionalmente concebido, permite que a noção de individualidade seja questionada. Mas também para os bósons em estado emaranhado, ou para o condensado de BoseEinstein (BEC), a identidade não faz sentido e, também nesta acepção dizemos que são não-indivíduos. Apesar de serem entidades indiscerníveis, há mais de uma entidade, o que contraria a individualidade entendida de forma leibniziana, fornecendo uma categoria ontológica completamente inédita em termos metafísicos.

\subsection{Questão metodológica}

A questão sobre se devemos tratar os objetos particulares através de uma ontologia de indivíduos ou uma ontologia de não-indivíduos, isto é, o problema filosófico sobre a natureza metafísica das entidades pode ser abordado, pelo menos, por duas metodologias diferentes, ambas com suas vantagens e desvantagens. O sentido me- 
todológico diz respeito ao tipo de visão utilizada para conduzir este tipo de investigação ontológica: se através de uma visão tradicional, ou através de uma visão naturalizada da metafísica (Para maiores detalhes sobre esta posição metodológica, ver Ladyman e Ross 2007).

A natureza metafísica dos objetos poderia ser fornecida por uma visão que considera a ontologia de forma independente das teorias científicas, a exemplo de uma 'filosofia primeira', que determina a priori como é a ontologia para os seres em geral através de suas categorias ontológicas já estabelecidas de antemão e, dessa forma, as teorias científicas não afetariam os seus pressupostos. Contrariamente, por uma via 'naturalizada', a resposta sobre a natureza metafísica dos objetos particulares é fornecida por uma ontologia que considera as teorias científicas para a sua informação, mais especificamente considera a mecânica quântica, por tratar do que há de mais fundamental dos objetos em geral. Destacamos ainda que essas duas abordagens apresentam uma diferença fundamental. A visão tradicional da metafísica sustenta uma ontologia única, universal, aos moldes de uma metafísica aristotélica, enquanto que uma visão naturalizada da metafísica, por levar em conta pressupostos científicos e por entender que a ciência progride, sustenta que qualquer ontologia ligada a ela teria um sentido provisório, por princípio, e um caráter investigativo disposto a mudança, procurando informar a metafísica a partir das nossas teorias científicas. Por esse motivo, uma ontologia através desta visão não poderia ser considerada acabada, mas em constante mudança, juntamente com a ciência na qual se baseia.

Assim, se seguirmos uma perspectiva ontológica naturalizada, a subdeterminação pode se estabelecer indicando-nos dois percursos: ou a aceitamos, como sugerem aqueles que defendem um realismo estrutural ontológico, ou fazemos uma escolha: se uma metafísica de indivíduos, ou uma metafísica de não-indivíduos. Claro que ainda há uma terceira forma de lidar com essa problemática, que obviamente não é a nossa opção, a qual propõe-se a adotar uma forma de quietismo metafísico. ${ }^{2}$ Nesse caso, deixamos de falar no assunto, dado que a teoria não nos permite dar uma resposta para a questão.

A visão tradicional da metafísica para uma investigação ontológica, por admitir uma ontologia única, já dita uma ontologia para os objetos em geral e, no final das contas, tudo é indivíduo. Seja através de teorias dos substratos, pelas quais sempre haverá uma 'essência' individualizadora e única a cada entidade, seja através das teorias de feixes de propriedades (Bundle Theories) — desde que se assuma a Lei de Leibniz - pelas quais os objetos são individualizados pelas suas propriedades intrínsecas, os seres em geral são enquadrados em uma categoria de indivíduos, incluindo as partículas quânticas. Por esse motivo, se considerarmos a perspectiva metodológica de uma metafísica aos moldes tradicionais, a individualidade é mantida como a única opção validada pelos princípios de individuação de modo geral e, dessa forma, a subdeterminação da metafísica pela física não faz sentido.

Principia 18(1): 67-85 (2014). 
No entanto, uma metafísica tradicional também poderia trabalhar com a noção de não-indivíduos. Devemos lembrar que a não-individualidade pode ser uma opção mesmo para metafísicos não naturalistas, como de fato ocorre com Lowe (2012) que classifica as entidades, segundo sua terminologia, em: pseudo-indivíduos, quaseindivíduos e sub-indivíduos, sendo todos tipos de não-indivíduos, mas todos diferentes entre si (Lowe 2012, p.14). O autor refere-se às "entidades as quais são determinantemente contáveis, mas nem sempre determinantemente identificáveis" (Lowe 1998, p.70). No entanto, concordando com a visão de French e Krause (2006), acreditamos que a noção de identidade deveria ser entendida em conformidade com algum tipo de lógica nesse caso, mas não fica claro, pela atribuição de Lowe, qual a lógica que se assume nessa discussão. Se for a lógica clássica, então os objetos de Lowe são semi-clássicos e, sendo assim, não podem representar as partículas quânticas como os não-indivíduos, segundo o contexto da Received View (Para maiores detalhes, ver French e Krause 2006, p.276).

Já, em uma metodologia naturalizada para abordar as questões ontológicas encontramos também defensores de uma ontologia da individualidade das entidades. Embora considerando as teorias científicas, alguns autores como Muller e Saunders (2008) tratam os objetos quânticos apenas como indivíduos, fomentando ainda mais as discussões sobre a individualidade. Nesse caso, a escolha da individualidade tenta justificar-se a partir da ideia de relativizar a discernibilidade através do conceito de 'discernibilidade fraca'. Este conceito é concebido a partir de reformulações do PII que possibilitam mantê-lo na disputa como princípio de individuação. Mas, tais justificativas embora tentem sustentar a individualidade dos objetos quânticos de modo a opor-se à noção dos não-indivíduos, ainda mostram-se controversas no propósito de individualização.

Ao nosso ver, algumas dificuldades com a noção de discernibilidade fraca, como critério de individuação, ainda permanecem. Muller e Saunders tentam reformular o princípio leibniziano de forma a considerar 'relações' no lugar de 'propriedades'. Nesse sentido, Arenhart e Krause (2012) observam que essa substituição consiste em um reducionismo leibniziano, pelo qual as diferenças por relações deveriam ser suficientes para determinar diferenças qualitativas. Mas o problema é que as relações não servem para diferenciar, pois isso seria admitir a individualidade das entidades através de suas qualidades extrínsecas.

Vejamos isso de outra forma. Se utilizarmos as propriedades para diferenciar os objetos particulares, recairemos em teorias de feixes de propriedades, cujos princípios individualizadores pressupõem na sua maioria das vezes o PII. Se seguirmos a sugestão de Muller e Saunders, as relações deverão fazer o papel de agente individualizador. No entanto, aceitar relações para discernir e individualizar, no sentido de fornecer individualidade aos objetos quânticos, levanta problemas metafísicos próprios, como aqueles onde as relações já assumem metafisicamente os objetos a 
serem relacionados. Como então definir a individualidade dos objetos, se esses já estão assumidos na relação?

Entendemos que considerar os não-indivíduos como entidade ontológica consiste em uma opção metafísica e não lógica, entretanto, se quisermos tratar as entidades quânticas como não-indivíduos, devemos esclarecer alguns pontos relativos às ferramentas teóricas formais para o tratamento dessas entidades.

\subsection{Questão lógica}

Uma das dificuldades relacionadas à esfera de ordem lógica diz respeito à lógica subjacente à teoria utilizada no tratamento dos não-indivíduos. Alega-se que, assumida a não-individualidade dos objetos quânticos, o PII é violado, uma vez que os nãoindivíduos são objetos que não respeitam as leis tradicionais da identidade da lógica clássica. Devemos entender que o sentido desta afirmativa diz respeito à pressuposição de utilizar a lógica clássica como lógica subjacente à mecânica quântica onde o PII, como alicerce a algum princípio de individuação, é um teorema e continua válido. Por isso, a representação formal dos não-indivíduos pode ser considerada pouco adequada, pois o tratamento dos não-indivíduos se processa através de um tipo de teoria, como a teoria de conjuntos ZF (Zermelo-Fraenkel), que tem como lógica subjacente, a lógica clássica. Nesta teoria os conceitos de indivíduo e identidade são tratados como conceitos inseparáveis e implicados entre si. Na verdade, o vínculo entre essas noções já é um comprometimento assumido pela teoria de conjuntos e, por isso, pode-se dizer que é uma teoria restrita à esfera da individualidade.

Assim, apenas às custas de recursos os não-indivíduos podem ser representados na teoria. Os físicos simulam os não-indivíduos dentro da teoria de conjuntos ZF por meio de classes de equivalência desenvolvidas por von Neumann. Lembramos, porém, que tais recursos devem ser inseridos ad hoc na teoria, porque todos os objetos do domínio de ZF são indivíduos, por princípio. Além disso, os não-indivíduos também encontram uma representatividade discutível, se considerarmos a lógica subjacente à teoria de conjuntos ZF. A lógica clássica subjacente à teoria ZF é uma lógica onde a identidade assume um valor absoluto e universal para todos os objetos do seu domínio. Dessa forma, a lógica clássica e a teoria de conjuntos as quais são utilizadas no formalismo da mecânica quântica estão fortemente comprometidas com os indivíduos e com a identidade.

Uma consequência direta relacionada com a noção de identidade prevista por ZF levanta algumas questões metafísicas a serem desenvolvidas, tais como a discussão de princípios individualizadores antes tidos como indisputáveis, como é o caso do PII. Um problema de consistência teórica também evidencia-se na questão lógica. Se uma coerência entre os pressupostos da teoria e a lógica subjacente em que ela (a teoria) se baseia deve ser buscado, então o uso de uma ferramenta teórica, como

Principia 18(1): 67-85 (2014). 
ZF e a lógica clássica, no tratamento dos não-indivíduos torna-se inadequado, se considerarmos que a identidade não faz sentido para os não-indivíduos.

Neste caso, concordamos com aqueles que defendem que uma lógica mais apropriada deve ser assumida no tratamento dessas entidades. Assim, assumir uma lógica onde a noção de identidade não seja absoluta, como é o caso da lógicas nãoreflexivas, além de assumir uma teoria onde os conceitos de indiscernibilidade e individualidade sejam conceitos desvinculados a princípio, pelo menos formalmente, parece-nos uma alternativa mais condizente com a tentativa de tratar os não-indivíduos de forma mais adequada, relativamente aos fundamentos da teoria. As lógicas de Schrödinger e a teoria de quase-conjuntos, por exemplo, são candidatas a essa tarefa (French e Krause 2006, cap.7).

Porém, também encontramos problemas de ordem formal que estão relacionados, de certa forma, com os problemas ontológicos, no sentido de que ainda falta uma semântica a contento para essas lógicas. A representação dos conceitos de identidade e individualidade é tratado de forma vinculada já na metalinguagem. Uma semântica para essas lógicas deveria ser aquela onde não houvesse implicação lógica entre essa noções, o que resultaria diretamente em uma maior liberdade para as interpretações metafísicas. Dessa forma, supostamente, os pressupostos metafísicos deveriam ser estabelecidos informalmente, à medida que uma lógica pudesse ser construída também sobre uma semântica intuitiva e informal.

Se pensarmos no caso de uma semântica intuitiva, a noção de não-individualidade apresenta uma dificuldade a ser superada em relação à sua própria metalinguagem. Entendemos que, nesse caso, a noção metafísica de não-indivíduo seria um pressuposto contraintuitivo, principalmente, por depreender-se que nós identificamos as coisas, em geral, à medida que as distinguimos umas das outras e os não-indivíduos não têm esta correspondência na metalinguagem.

Uma alternativa seria considerar a teoria de quase-conjuntos como semântica para as lógicas de Schrödinger. E, por outro lado, as lógicas de Schrödinger poderiam desempenhar satisfatoriamente o papel de sustentar uma teoria quase-conjuntista, como sua lógica subjacente. Fica clara a circularidade que se estabelece. Mas, igualmente, essa circularidade também ocorre com ZF e a lógica clássica, e não é determinante que tais pressupostos ontológicos formais também devam ser a priori e não possam ser articulados em uma segunda abordagem. A construção de uma teoria pode iniciar-se, primeiramente, de forma intuitiva e informal, contanto que em um segundo momento possamos retornar aos seus pressupostos e fundamentá-los adequadamente, pois, concordando com Kunen, “[...] a lógica formal deve ser desenvolvida duas vezes." (Kunen 2009, p.191). Por exemplo, podemos assumir informalmente a teoria dos quase-conjuntos como uma metateoria de onde construiremos os conceitos lógicos e, a partir de então, redefinimos novamente aqueles conceitos que tínhamos de forma intuitiva, agora porém, através de uma conceituação mais 
rigorosa, mais precisa e adequadamente fundamentada. Desta forma, pressupostos lógicos e ontológicos poderiam formar-se, partindo de um mesmo plano de discussão em direção à construção de uma semântica dos não-indivíduos.

Acreditamos que as dificuldades abordadas não se reduzem apenas ao âmbito filosófico, mas podem ser ampliadas também a uma esfera pragmática, no sentido de adequar a uma categoria ontológica advinda da mecânica quântica o rigor dos conceitos envolvidos nas teorias disponíveis. Uma tentativa de dar conta dessa dificuldade apresenta-se através de uma fundamentação formal mais rigorosa no tratamento dessas entidades.

\section{Assumindo os não-indivíduos}

Fornecer argumentos a favor de uma das visões metafísicas consistentes com os dados científicos significa assumir algumas prerrogativas. A primeira delas refere-se a dar sentido ao termo 'subdeterminação da metafísica'. A princípio, seria necessário assumir uma visão metodológica naturalizada de ontologia, caso contrário, sob uma visão tradicional da metafísica, possibilidades ontológicas advindas de teorias científicas não são relevantes ou, pelo menos, não são a fonte primária da nossa ontologia.

Em segundo lugar, assumimos que os pressupostos de ordem metafísica envolvidos devam ser considerados para uma construção ontológica dos seres em geral, em conformidade com as teorias científicas. Parece-nos que sem os recursos da teoria, que poderiam apoiar uma decisão, a escolha sobre qual ontologia devemos seguir para referir-nos às entidades metafísicas caberia a nós. Entretanto, "apelar para virtudes não empíricas, as chamadas virtudes teóricas, é visto por muitos filósofos como ilegítimo" (Krause e Arenhart 2013, p.162), uma vez que não há razões para acreditar que uma ontologia possa ser melhor candidata que outra, expandindo a dificuldade igualmente à opção dos não-indivíduos. Também os pressupostos de ordem lógica deveriam ser reconsiderados relativamente aos seus conceitos primitivos, de forma a representar as características das entidades sem identidade.

Argumentamos que uma ontologia de não-indivíduos ainda pode ser a opção mais plausível por várias razões. A motivação principal pretende preservar uma visão ontológica naturalizada, alinhada às considerações da Received View. Além disso, as entidades destituídas de individualidade (aqui, lembrando que estamos tratando a individualidade segundo a concepção leibniziana) são consistentes com as observações científicas, uma vez que são oriundas das observações das distribuições estatísticas quânticas. Entendemos, no entanto, que assumir os não-indivíduos não se refere apenas a uma problemática ontológica, no sentido de questionar os princípios de individuação, mas também os princípios lógicos são questionáveis, tornando-se

Principia 18(1): 67-85 (2014). 
também uma problemática formal. Assim, partindo de uma conduta metodológica naturalizada, argumentamos a favor dos não-indivíduos, focalizando duas esferas: (i) a ontológica, na qual os princípios de individuação falham em dar conta de uma exclusividade da individualidade, como o PII; e, (ii) a lógica, na qual a utilização de uma lógica adequada possa permitir uma representação formal dessa nova categoria ontológica.

A primeira dificuldade que a noção da não-individualidade traz refere-se a sua abordagem. Quando concebida de modo informal, a noção de indivíduo vem carregada de um pressuposto muito difundido, baseado em nossas intuições leibnizianas, que torna os conceitos de identidade e indiscernibilidade interdependentes. Considerar um dos conceitos sem esbarrar no outro parece contraintuitivo, originando um desafio em relação a como devemos entender a não-individualidade, sobretudo, porque os princípios baseados no PII mostram-se ineficazes nesse aspecto. Mas há autores que discordam dessa ineficácia e propõem uma reformulação do princípio, de modo a preservá-lo como princípio de individuação. Isto é, mesmo uma falha do PII poderia ser admitida pelas diversas formulações do princípio, as quais já vêm sendo associadas às teorias da individualidade.

Como já mencionamos, autores como Muller e Saunders defendem a individualidade dos objetos quânticos, baseando-se nessas reformulações, ainda sob a perspectiva de uma metafísica naturalizada. Segundo os autores (2008), o PII ainda mantém-se na disputa como princípio de individuação através de uma relativização da indiscernibilidade no princípio. Há, pela visão dos autores, três versões do PII pelas quais os objetos seriam: absolutamente indiscerníveis, relativamente indiscerníveis, ou absoluta e relativamente indiscerníveis. O princípio, supostamente, resistiria, se dois objetos relativamente indiscerníveis apresentarem algum tipo de distinção relacional que os autores denominam como entidades absolutamente indiscerníveis não-idênticas. De modo geral, as relações assimétricas e reflexivas são condições suficientes para a discernibilidade, como ocorre de fato na descrição leibniziana, mas o que Muller e Saunders defendem é que não são condições necessárias. Nesta perspectiva, a discernibilidade fraca é uma discernibilidade relativa fornecida pelas relações simétricas e irreflexivas (Muller e Saunders 2008, p.504). A notação n-discernibilidade é sugerida para uma 'discernibilidade relacional', significando que objetos são discerníveis por algum tipo de relação $n$-ária, ou seja, por alguma relação de peso $n$, por exemplo, 'ter spin oposto a', para o caso de férmions. Neste caso, dois férmions seriam fracamente discerníveis entre si, pois estariam em uma relação simétrica e irreflexiva: 'ter spin oposto a' discerne o elétron pela irreflexividade, mas não pela simetria. Dessa forma, uma hierarquia infinita de princípios de indiscernibilidade segue, cada qual, mais fraca que a sua discernibilidade relacional sucessora, no caso de mais de dois elétrons. Diferentemente da formulação tradicional, as reformulações do PII, defendidas por Muller e Saunders, admitem as relações, ou seja, 
admitem as qualidades extrínsecas como critério de individualidade. Mas, embora os autores argumentem que as entidades quânticas são indivíduos, devemos lembrar que isso não lhes confere a individualidade ${ }^{3}$ na acepção que estamos argumentando, ou seja, no sentido leibniziano, concebido tradicionalmente. Além disso, a definição da discernibilidade relativa e absoluta, segundo os autores, é logicamente disjuntiva, mas a utilização de relações no escopo do PII ainda é um tema controverso. Arenhart (2012a) lembra que, para a maioria dos filósofos, as relações não deveriam ser permitidas na formulação do PII. Vejamos o argumento.

$\mathrm{Na}$ física clássica, as relações descritas como espaço-temporais sustentam uma forma mais fraca do PII, denominada PII(1), que considera como propriedades as relações espaço-temporais, no sentido que, se não for possível discernir objetos indiscerníveis pelas suas propriedades intrínsecas, ainda assim restaria a distinção espaçotemporal, argumentando-se favoravelmente à distinção quantitativa, pois a distinção de objetos macroscópicos pela relação espaço-temporal pode ser mantida pela condição da impenetrabilidade, pressuposto fundamental da física clássica. Contudo, a aplicabilidade da forma mais fraca do PII às partículas quânticas torna-se problemática devido ao fenômeno de superposição de estados, pois, quando tratamos com inobserváveis, segundo uma interpretação ortodoxa da mecânica quântica, as propriedades intrínsecas e a relação entre a continuidade temporal e a localidade não são mais observadas.

As diferenças por relações deveriam ser suficientes para determinar diferenças qualitativas, mas como elas não apresentam uma característica discernível entre itens discerníveis, não se pode contar com as suas diferenças como sendo qualitativas (Arenhart 2012a, p.8-9). Se considerarmos o PII formulado na sua forma tradicional, que diz que os objetos que compartilham as mesmas propriedades são o mesmo objeto, necessariamente a indiscernibilidade estará atrelada à noção de identidade.

Uma alegação que leva em conta as relações para uma descrição metafísica da individualidade seria insatisfatória, se quisermos tomar os objetos particulares como entidades metafísicas mais fundamentais e, nesse caso, as relações seriam atributos potenciais dos objetos. Alegar relações ou objetos relacionais acabaria por adicionar mais uma entidade metafísica a ser considerada, ou resultaria em um realismo estrutural ontológico no qual os objetos particulares, considerados em segundo plano, seriam derivados das relações, e não o contrário.

Entretanto, nem sempre tratar a ontologia de forma naturalizada implica admitir a não-individualidade. No século XX, uma das tendências filosóficas analíticas mais reconhecidas de conceber a ontologia de forma a tratar a metafísica sob uma dimensão mais naturalizada foi fundamentada por Quine em muitos de seus trabalhos. Segundo Quine, em On what there is, uma entidade, para existir em uma teoria que a concebe, deve poder ser quantificada nessa teoria, o que ele expressa através da 
máxima 'ser é ser o valor de uma variável'. Essa máxima resume tanto o critério de comprometimento ontológico de uma teoria, bem como o contexto no qual ela se insere, significando que em uma teoria as noções de quantificação, identidade e entidade estão imbricadas entre si (Quine 1961, p.13-5). Quine também argumenta em um artigo de 1976, intitulado Whither physical objects, que o desenvolvimento da física no século passado sustenta que o conceito de objeto físico 'evaporou' como partícula elementar fundamental (referindo-se aos objetos sem identidade que a mecânica quântica revelou) e nada além de regiões no espaço-tempo comportariam certas propriedades do objeto. Como solução alternativa para preservar a identidade e, assim, a individualidade dos objetos, Quine sugere uma redução ontológica do seguinte modo: ele propõe identificar os objetos físicos com uma região espaçotemporal que eles 'ocupam' e depois identificar esta região espaço-temporal através de uma conjunto de quadruplas de números reais, isto é, três coordenadas no $R^{3}$ e uma coordenada temporal $(x, y, z, t)$ que podem ser descritas através de um conjunto numérico (Chateaubriand 2003, p.61). Tal sugestão pretende responder a questão sobre o critério de identidade da partícula elementar e sua correspondente quantificação, uma vez que identidade e quantificação estariam implicadas necessariamente para Quine. Nesse sentido, a base de sua ontologia estaria reduzida a uma teoria de conjuntos: uma ontologia do objeto físico seria uma ontologia de conjuntos de quádruplas. Desde que a teoria de conjuntos envolvida nessa acepção quiniana de ontologia possa ser considerada como sendo a teoria de conjuntos ZF com o axioma da extensionalidade, fica subentendida a suposição da noção de identidade nos fundamentos teóricos que sustentam essa ontologia. E, dessa forma, para Quine, os objetos físicos quânticos seriam indivíduos, já que podem ser quantificados e, por isso, há algum critério de identidade aplicado. Um exemplo claro da redução ontológica de Quine também evidencia-se na sua famosa frase "Não há entidade sem identidade", sugerindo o grau de significação que o conceito de identidade assume na sua ontologia, o que significa que o comprometimento ontológico é relativo à teoria de conjuntos padrão (como ZF) com identidade (Uma boa perspectiva das principais ideias de Quine pode ser encontrada em Chateaubriand 2003). Portanto, qualquer outra teoria de conjuntos que teria por base fundacional uma lógica não-reflexiva na qual a identidade fosse questionada (ou até mesmo eliminada), como as lógicas de Schrödinger, não seria aceitável para Quine (Para maiores detalhes, ver Dalla Chiara e Toraldo di Francia 1995, p.104-11; French 1998, p.93-4).

Mas, considerar a quantificação apenas para objetos com identidade é uma decisão metafísica que pode ser questionada, se pensarmos na utilização desse pressuposto como uma ferramenta de critério ontológico acerca da existência ou não das entidades sem identidade (Arenhart e Krause 2009). Para alguns autores como Quine, por exemplo, os objetos físicos são tidos sob uma perspectiva de indivíduos por serem considerados dentro de uma lógica de domínio mais restrito, ou seja, 
um domínio determinado por uma lógica de primeira ordem com identidade. Como a Received View considera o 'surgimento' dos não-indivíduos como entidades destituídas de individualidade através de uma ontologia advinda da teoria científica, os não-indivíduos na concepção da Received View não serão entidades na concepção quiniana, a qual admite o PII como princípio fundamental de individuação, além de admitir, como única lógica subjacente, a lógica clássica de primeira ordem em cujo domínio de quantificação deverão constar as entidades da teoria.

Segundo nosso ponto de vista, concordante com a concepção pragmatista de da Costa, os princípios lógicos devem ser flexíveis, ou dialetizáveis, e conformativos às necessidades das teorias científicas (Da Costa 1980, p.116). Assim, quando dizemos que a mecânica quântica pode comprometer-se com entidades destituídas de individualidade, devemos dar conta dessas entidades ontológicas, antes não concebidas por uma visão de ontologia tradicional, mesmo que para isso tenhamos que assumir outras bases lógicas não-clássicas com novos princípios, de modo a estar de acordo com os dados empíricos advindos das teorias científicas. Por essa perspectiva, a lógica não poderia ser única, mas, ao contrário, teria um caráter relativo às teorias científicas. Uma lógica não-reflexiva, como as lógicas de Schrödinger, por exemplo, ajusta-se à ideia de que representar a quantificação de suas entidades independe da identidade, ou seja, a identidade não faz sentido para todas as entidades do domínio. No entanto, uma das maiores críticas a essas lógicas é a falta de uma semântica apropriada, já que devemos dar conta de uma semântica onde a quantificação de objetos sem identidade não está descartada (Da Costa e Krause 1994).

O propósito de fundamentar formalmente uma ontologia de não-indivíduos motivou o desenvolvimento de lógicas alternativas e de uma teoria matemática cuja fundamentação teórica pudesse sustentar tais noções metafísicas. Se assumirmos que a lógica clássica não é mais única, nem fixa, nem absoluta, não se pode assumir uma 'lógica verdadeira' e, consequentemente, abrem-se possibilidades para se pensar em um pluralismo lógico, onde uma mudança de lógica acarreta mudanças ontológicas (Krause 2004, p.77). Nesse sentido, pode-se contrariar a famosa frase de Quine que afirma 'Não há entidade sem identidade' pois, pela nossa argumentação, os objetos quânticos indiscerníveis, isto é, objetos sem identidade, podem ser vistos como entidades sem individualidade, ou seja, como não-indivíduos, e podem figurar no domínio de quantificadores de adequadas lógicas ou teorias 'regimentadas' sobre essas lógicas (Krause 2007).

Outro ponto para se argumentar a favor dos não-indivíduos refere-se à relação que podemos estabelecer entre as propriedades e as lógicas não-reflexivas. Uma das alternativas de tratar a individualidade como propriedade torna-se interessante no sentido de podermos formalizá-la. Em um artigo de 1963, Heinz Post denominou 'individualidade transcendental' (TI) ao tratamento da individualidade como se fosse um thisness. O conceito de TI consiste, genericamente, em assumir um substrato 
inerente às propriedades como responsável pela individualidade dos objetos e, dessa forma, não seria necessário requerer o PII, que baseia-se em propriedades, como modo de individuação. Na verdade, a TI de Post é um substrato primitivo que 'possui a propriedade de ser ele mesmo', gerando uma autoidentidade (French e Krause 2006, p.13).

Assumir uma forma de TI, aos moldes de Post (Post 1963), traz certa vantagem à defesa dos não-indivíduos pois, embora considerando a individualidade de modo transcendental, ela poderia ser descrita como uma propriedade reflexiva de autoidentidade. $\mathrm{O}$ interessante nesse caso, ao tratar a individualidade como um primitive thisness, é que uma propriedade autorreflexiva (ou a autoidentidade) pode ser formalizada como $\forall x(x=x)$ e, consequentemente, se violarmos essa propriedade, poderemos captar a noção de que essa lei não é universal. Não se trata, aqui, de negar a individualidade, mesmo porque defendemos a ausência de individualidade para determinadas entidades quânticas, mas, sim, admitir que a propriedade de autoidentidade não se aplica a todos os elementos do domínio, o que acarretaria obter uma representação formal da não-individualidade.

Esse é um foco central nas considerações sobre a construção de um sistema de lógica como as lógicas de Schrödinger (Para maiores detalhes ver Da Costa, 1980; Da Costa e Krause 1994). Um dos aspectos principais dessas lógicas consiste na possibilidade de derrogar o princípio de identidade a fim de possibilitar o tratamento de entidades como os não-indivíduos desde os conceitos primitivos da teoria. Segundo Post, a não-individualidade deveria ser tratada desde o início, isto é, desde os fundamentos da teoria, opondo-se aos recursos ad hoc demandados pela teoria de conjuntos ZF no tratamento das partículas quânticas. A teoria de quase-conjuntos, por exemplo, propõe-se a tratar os não-indivíduos nesses moldes, onde a noção de indiscernibilidade é assumida já nos conceitos primitivos da teoria como uma noção mais fraca de identidade (Para maiores detalhes, ver French e Krause 2010, p.103; French e Krause 2006, cap. 7).

\section{Final}

A opção de escolha sobre a natureza das entidades a serem tratadas pela mecânica quântica, seja a favor dos não-indivíduos ou mesmo dos indivíduos, envolve aceitar outros tipos de pressupostos e argumentos que não apenas aqueles fornecidos pela teoria científica em questão. Neste sentido, este impasse acaba encerrando-se em pressupostos metafísicos de qualquer forma: uma ontologia de indivíduos ou uma ontologia de não-indivíduos são igualmente opções de ordem metafísica. Algumas alternativas consistem em aceitar uma teoria metafísica pelo fato de que ela é mais simples, ou mais elegante, ou é mais condizente com determinados fenômenos. Não

Principia 18(1): 67-85 (2014). 
há razões lógicas nem formais que nos indicam uma escolha, mas qualquer que seja ela, esta deverá estar fundamentada em bases lógicas e metateóricas consistentes com aquilo que propõem-se a representar. Por isso, à medida que apresentamos uma fundamentação formal mais adequada para o tratamento das entidades quânticas, os não-indivíduos tornam-se uma possibilidade plausível e podem ser legitimamente representados pelos conceitos que a teoria propõe desde os seus fundamentos, de forma a obter consistência entre os pressupostos teóricos (no caso, pressupostos formais) e os dados científicos.

Além disso, parece-nos que, dependendo da teoria a qual retrata a porção de realidade considerada, uma lógica específica poderá ser mais adequada a cada caso, o que torna a condição da lógica nas teorias científicas relativa. Dessa forma, embora o desejo de fundamentar uma ontologia de não-indivíduos em uma lógica nãoreflexiva possa ser oriundo de fatores puramente filosóficos, a aplicabilidade de determinada lógica nos contextos científicos deve-se a uma atitude pragmática.

Entendemos que assumir os não-indivíduos também apresenta dificuldades. Uma delas, talvez a maior, é que não podemos tratar os não-indivíduos ontologicamente como os objetos do dia-a-dia pelos mesmos critérios imputados aos objetos macroscópicos. Objetos sem identidade não têm representação na metalinguagem, pois é contraintuitivo conceber entidades sem identidade.

Nesse caso, poder representar e tratar os não-indivíduos, pelo menos formalmente, torna-se uma vantagem. À medida que utilizamos uma teoria, como a teoria de quase-conjuntos a qual, desde seus conceitos primitivos, pode tratar de coleções de objetos que não são indivíduos, ou seja, objetos que não respeitam as leis tradicionais da identidade da lógica clássica; e, à medida que também utilizamos as lógicas não-reflexivas, nas quais a identidade não se aplica a todos os objetos do domínio, estaremos contribuindo com maior coerência e maior adequação entre os pressupostos teóricos utilizados para tratar as entidades quânticas e a lógica subjacente a esses pressupostos.

Além disso, uma perspectiva naturalizada da metafísica ainda seria preservada, ao se considerar uma nova categoria ontológica como os não-indivíduos, abrindo possibilidades para um pluralismo ontológico.

Contudo, se a abordagem naturalista tem raízes (científicas) na concepção ortodoxa da mecânica quântica em relação ao objeto físico por um lado, por outro, pressupostos ontológicos não naturalizados, ditos tradicionais, parecem também ter espaço, uma vez que a própria teoria não nos indica como devemos tratar a partícula, destituindo a teoria científica como fonte exclusiva para o conhecimento científico.

Claro que existe a preocupação, como observa French, de que grande parte da metafísica moderna parece ter se distanciado de qualquer fundamentação na física moderna, o que levaria a um modelo normativo que apela para princípios extraídos de uma 'metafísica sem física'. Essa é uma das preocupações que está nas bases da

Principia 18(1): 67-85 (2014). 
concepção de um realismo estrutural ontológico. Os defensores dessa perspectiva acreditam que apelar à metafísica parece deixar-nos com um dilema: ou a metafísica flutua livre da física e requer uma justificação própria, ou ela é contínua à física e continua subdeterminada. Isto é, para o autor, o apelo à metafísica para as considerações sobre a natureza das entidades configuraria um afastamento da ciência como fonte para informar a sua ontologia (French 2011, p.209-10).

Embora exista tal preocupação, entendemos que a polaridade desse dilema apontado por French pode ser flexibilizada. Uma alternativa seria uma intermediação entre essas duas possibilidades de ver a metafísica: tradicional e naturalizada (Arenhart 2012, p.355). Assumir que há espaço para considerações metafísicas não significa que a teoria científica deva ser abandonada ou ignorada nos moldes de uma metafísica tradicional mas, antes, admitir apenas que ela não é a fonte exclusiva de nosso conhecimento acerca de determinadas características do mundo, como pretendiam aqueles que defendiam a Received View. Essa condição envolveria não apenas recusar uma exclusividade científica na investigação ontológica dessas entidades, mas também aceitar outros tipos de pressupostos de caráter puramente metafísico. Uma ontologia dos não-indivíduos pode ser sustentada, utilizando o melhor das nossas teorias científicas para uma visão crítica das categorias ontológicas já pressupostas pela metafísica tradicional, mas também devemos admitir que, ao utilizar as nossas teorias científicas, já estamos de algum modo contaminados pelas nossas categorias metafísicas. Um avanço para qualquer um dos lados dar-se-ia através de uma dialética crítica, pela qual novas categorias ontológicas poderiam ser admissíveis, como também pressupostos que não se baseiam completamente nas teorias científicas, ou seja, aspectos metafísicos deveriam ser levados em conta. De um modo claro esta perspectiva aproxima valores metafísicos de credenciais científicas através de uma relação dinâmica, crítica e pragmática, a nosso ver construtiva, entre a metafísica e a ciência.

\section{Referências}

Arenhart, J.R.B. 2012. Ontological Frameworks for Scientific Theories. Foundations of Science 17: 339-56.

- 2012a. Weak discernibility in quantum mechanics: does it save PII? Axiomathes doi: 10.1007/s10516?012?9188?x.

Arenhart, J. R. B.; Krause, D. 2009. Quantifiers and the Foundations of Quasi-Set Theory. Principia 13(3): 251-68.

—. 2012. Indistinguibilidade, não reflexividade, ontologia e física quântica. Scientiae Studia 10(1): 41-69.

Chateaubriand, O. 2003. Quine and Ontology. Principia 7(1-2): 41-74.

Da Costa, N. C. A. 1994 [1980]. Ensaios sobre os Fundamentos da Lógica. $2^{a}$ ed. São Paulo: Hucitec/EdUSP.

Principia 18(1): 67-85 (2014). 
Da Costa, N. C. A.; Krause, D. 1994. Schrödinger Logics. Studia Logica 53: 533-50.

Dalla Chiara, M. L.; Toraldo Di Francia, G. 1995. Quine - On Physical Objects. In: P. Leonardi (ed.) On Quine: New Essays 7, Cambridge: Cambridge University Press, p.104-12.

French, S. 1998. On the withering away of Physical Objects. In: E. Castellani (ed.) Interpreting Bodies, New Jersey: Princeton University Press, p.93-113.

- 2011. Metaphysical Underdetermination: why worry? Synthese 180: 205-21.

French, S.; Krause, D. 2006. Identity in Physics: A Historical, Philosophical and Formal Analysis. Oxford: Oxford University Press.

- 2010. Remarks on the Theory of Quasi-Sets. Studia Logica 95: 97-120.

French, S.; Rickles, D. 2003. Understanding Permutation Symmetry. In: K. Brading; E. Castellani (eds.) Symmetries in Physics - Philosophical Reflections, Cambridge: Cambridge University Press, p.212-238.

Krause, D. 2004. Lógica Paraconsistente. Scientific American Brasil, Ed. Nov.: 70-7.

- 2007. Entity, but no Identity. Disponível em: http://philsci-archive.pitt.edu/3283/. Acesso em: 07/08/13.

Krause, D.; Arenhart, J.R.B. 2013. Perspectivism in Philosophy of Science: A Case-Study in Quantum Physics. Scientiae Studia 11(1): 159-183.

Kunen, K. 2009. The Foundations of mathematics. London: College Publications.

Ladyman, J.; Ross, D. 2007. Everything must go: Metaphysics Naturalized. Oxford: Oxford University Press.

Lowe, E. J. 1998. A Possibility of Metaphysics - Substance, Identity and Time. Oxford: Clarendon Press.

- 2012. Non-Individuals. Pre-print for the Conference on 'Individuals Across Sciences: A Revisionary Metaphysics?', Paris, 18-20 May 2012.

Muller, F. A.; Saunders, S. 2008. Discerning Fermions. British Journal for the Philosophy of Science 59: 499-548.

Post, H. 1973 [1963]. Individuality and Physics. The Listener, 10 de outubro, p.534-7. Reimpresso em Vedanta for East and West 132: 14-22.

Quine, W. v. O. 1961. On what there is. The Review of Metaphysics 2: 21-38. Reprinted with additions In: W. v. O. Quine, From a Logical Point of View, p.1-19.

Schrödinger, E. 1935. Science and the Human Temperament. Latimer Trend and Co.: Plymouth, Great Britain.

Virvidakis, S.; Kindi, V. 2006. Quietism. Disponível em: http://www.oxfordbibliographies.com/view/document/obo-9780195396577/obo-9780 195396577-0184.xml?rskey=QQIZYz\&result=1\&q=quietism\#firstMatch. Acesso em: $28 / 07 / 2013$.

VALÉRIA GRADINAR Universidade Federal de Santa Catarina Programa de Pós-Graduação em Filosofia valgradinar@gmail.com

Resumo. A mecânica quântica não-relativística nos oferece condições de considerar, pelo menos, dois pacotes metafísicos possíveis, porém incompatíveis: uma metafísica de indivíduos e uma metafísica de não-indivíduos. Além disso, o formalismo padrão é compatível

Principia 18(1): 67-85 (2014). 
com ambas as ontologias, sem que a teoria decida por nenhuma delas. É a partir de uma situação como esta que a tese da subdeterminação da metafísica pela física pode se estabelecer. Encontramos atualmente, entre cientistas e filósofos, aqueles que advogam por uma ontologia ou pela outra, como também há aqueles que não se pronunciam sobre a questão, dado que a teoria, por si só, não a decide. Isso significa que, caso se opte por um desses pacotes, a escolha acaba sendo de ordem metafísica, fomentando muito as discussões filosóficas sobre a individualidade dos objetos quânticos no contexto da física quântica. Partindo de uma conduta metodológica naturalizada, apresentamos os argumentos daqueles que defendem a individualidade dos objetos quânticos e daqueles que defendem, como nós, a não-individualidade, focalizando duas abordagens: (i) a ontológica, na qual a falha do PII, como princípio de individuação, é discutida; e, (ii) a lógica, na qual uma lógica não-reflexiva como também uma teoria quase-conjuntista tornam-se mais adequadas para representar os não-indivíduos. Neste artigo defendemos que a escolha de uma ontologia de não-indivíduos torna-se mais plausível e deve ser levada em conta seriamente, abrindo possibilidades para um pluralismo ontológico.

Palavras-chave: Subdeterminação metafísica; mecânica quântica; não-indivíduos.

\section{Notas}

${ }^{1}$ Neste artigo, consideraremos apenas a interpretação ortodoxa da mecânica quântica nãorelativista, ou também como é conhecida 'interpretação de Copenhague', mesmo quando mencionarmos somente 'mecânica quântica'.

2 De forma geral, o 'quietismo' na filosofia analítica contemporânea é a visão ou postura que implica evitar a teorização filosófica da substância, além de ser geralmente associada a certas formas de ceticismo, pragmatismo e minimalismo sobre a verdade. Mais particularmente, é uma visão que opõe-se a teses positivas que possam desenvolver argumentos construtivos. O quietismo foi invocado recentemente, principalmente por pensadores wittgensteinianos e neopragmáticos, embora tenha sido criticado por defensores de posicionamentos realistas (Para mais informações, ver Virvidakis e Kindi 2006).

${ }^{3}$ Claro que partículas, átomos e etc. podem ser isolados dos demais no sentido de separá-los de outros do mesmo tipo, mas isso não lhes confere a individualidade na acepção de Leibniz, pois não podemos identificá-los como este ou aquele, como bem ilustra o filme $O$ menino e seu átomo da IBM. Esse filme acompanha uma matéria sobre nanotecnologia, publicada pela Revista Exame em 06/05/2013 e pode ser acessado em: http://exame.abril.com.br/tecnologia /noticias/ibm-produz-menor-filme-do-mundo-com-atomos?page=2.

Principia 18(1): 67-85 (2014). 